\title{
Producción de un antisuero policlonal para la detección de Cymbidium mosaic virus y Odontoglossum ringspot virus en orquídeas
}

Dottori, C. A., de Breuil, S., Tuma, M. A. y Nome, C. F.

DOI: $10.31047 / 1668.298 x . v 37 . n 2.28268$

\begin{abstract}
RESUMEN
Las orquídeas (familia Orchidaceae) son susceptibles a diversos factores bióticos y abióticos que afectan su desarrollo y calidad. Entre ellos, Cymbidium mosaic virus (CymMV) y Odontoglossum ringspot virus (ORSV) son los patógenos más frecuentes y de mayor importancia económica a nivel mundial. La transmisión mecánica de estos virus y la multiplicación principalmente agámica de las orquídeas hacen necesario contar con material madre libre de virus. El objetivo de este trabajo fue elaborar reactivos de diagnóstico para la detección de CymMV y ORSV. Se elaboró un antisuero policlonal contra CymMV+ORSV que se tituló 1:10000 mediante NC-ELISA. El antisuero fue procesado y se obtuvieron IgG e IgG-conjugada anti CymMV+ORSV dilución 1:500 para su utilización en DAS-ELISA. La capacidad inmunodiagnóstica de esta técnica se evaluó mediante el análisis de muestras provenientes de orquídeas con síntomas característicos de infección viral, recolectadas en viveros comerciales de la ciudad de Córdoba, Argentina. La presencia de virosis se detectó en el $22 \%$ de las muestras estudiadas y en el $75 \%$ de los establecimientos relevados. La capacidad de estos reactivos para identificar CymMV, ORSV e infecciones mixtas en orquídeas permitirá agilizar y economizar los análisis. Esto representaría una ventaja para las detecciones a gran escala.
\end{abstract}

Palabras clave: orquídeas; fitovirología; diagnóstico; antisuero.

Dottori, C. A., de Breuil, S., Tuma, M. A. and Nome, C. F., 2020. Production of polyclonal antiserum for the detection of Cymbidium mosaic virus and Odontoglossum ringspot virus in orchids. Agriscientia 37 (2): 45-51

\section{SUMMARY}

Orchids (family Orchidaceae) are susceptible to several biotic and abiotic factors that affect their development and quality. Among them, Cymbidium mosaic virus (CymMV) and Odontoglossum ringspot virus (ORSV) are the 
most frequent pathogens, with the greatest economic impact worldwide. The mechanical transmission of these viruses in addition to the predominantly agamic multiplication of orchids, make it necessary to work with virus-free plant material. The objective of this work was to develop diagnostic reagents for the detection of CymMV and ORSV. A polyclonal antiserum against CymMV + ORSV was made with a titer of 1:10000 determined by NC-ELISA. The antiserum was processed generating IgG and IgG-conjugated" anti CymMV+ORSV were obtained for use in DAS-ELISA in a dilution of 1:500. The immunodiagnostic capacity of this technique was evaluated by analyzing samples from orchids with characteristic viral symptoms, collected from commercial nurseries in the city of Córdoba, Argentina. Viral infections were detected in $22 \%$ of the samples analyzed and in $75 \%$ of the nurseries surveyed. The ability of these reagents to identify CymMV, ORSV and mixed infections in orchids, will speed up analyzes and reduce their costs. This would represent an advantage for large-scale detections.

Key words: orchids; phytovirology; diagnosis; antiserum.

Dottori, C. A. (ORCID: 0000-0002-2568-4651) Instituto de Patología Vegetal, Centro de Investigaciones Agropecuarias (IPAVE-CIAP), Instituto Nacional de Tecnología Agropecuaria (INTA). Av. 11 de Septiembre 4755 (X5014MGO), Córdoba, Argentina. de Breuil, S. (ORCID: 0000-0001-7513-372X) y Nome, C. F. (ORCID: 0000-00029727-108X): Instituto de Patología Vegetal, Centro de Investigaciones Agropecuarias (IPAVE-CIAP), Instituto Nacional de Tecnología Agropecuaria (INTA). Av. 11 de Septiembre 4755 (X5014MGO), Córdoba, Argentina. Unidad de Fitopatología y Modelización Agrícola (UFyMA)-INTA-CONICET. Av. 11 de Septiembre 4755 (X5014MGO), Córdoba, Argentina. Tuma, M. A.: Facultad de Ciencias Agropecuarias, Universidad Nacional de Córdoba. Ing. Agr. Felix Aldo Marrone 746, Ciudad Universitaria, CP 5000, Córdoba, Argentina. Correspondencia a: nome.claudia@inta.gob.ar

\section{INTRODUCCIÓN}

Las orquídeas son monocotiledóneas pertenecientes a la familia Orchidaceae, clasificadas en más de 700 géneros que incluyen unas 25.000 especies. Son plantas cosmopolitas que crecen principalmente en los trópicos y subtrópicos, aunque existen especies que se desarrollan en zonas templadas y frías (Freuler, 2007). Al igual que la mayoría de las plantas, las orquídeas se reproducen de forma sexual y asexual. La reproducción sexual garantiza una mayor diversidad genética y, por ende, fenotípica. Sin embargo, la principal forma de reproducción utilizada por coleccionistas y comerciantes es la asexual, en la cual la nueva planta se obtiene a partir de fracciones de la planta madre favoreciendo así la propagación y diseminación de enfermedades, especialmente las de etiología viral (Zettler, Ko, Wisler, Elliott y Wong, 1990; Hartmann y Kester, 1991). Las orquídeas pueden ser multiplicadas a gran escala mediante técnicas de micropropagación originando clones perfectos de la planta original (planta madre) (Arditti y Ernst, 1993). La propagación de meristemas es un método muy útil para la multiplicación masiva de variedades de calidad destacada y especialmente de híbridos, pero requiere de material madre de excelente calidad sanitaria.

En el mundo se han reportado varios virus que afectan diferentes géneros de orquídeas. Entre ellos, Cymbidium mosaic virus (CymMV) y Odontoglossum ringspot virus (ORSV) son los patógenos más relevantes desde el punto de vista económico debido a los daños que ocasionan y a la elevada prevalencia e incidencia que tienen a nivel mundial (Zettler et al., 1990). Ambos virus se transmiten de una planta infectada a otra sana por contacto mecánico y su dispersión se ve favorecida por la propagación agámica de estas especies (Wong, Chng, Lee, Tan y Zettler, 1994; Rani, Pant y Jain, 2010; Pradhan, Regmi, Ranjit y Pant, 2016). Hasta la fecha no se ha demostrado su transmisión a través de semillas y no se conocen 
insectos vectores de estos patógenos.

En el año 2010 en Argentina se reportaron por primera vez ambos virus en orquídeas del género Oncidium producidas bajo cubierta en la provincia de Buenos Aires (Cánovas, Ballari y Nome, 2016). CymMV pertenece al género Potexvirus, de la familia Alphaflexiviridae; es un virus monopartito, elongado flexuoso de aproximadamente $480 \mathrm{~nm}$ de longitud (Lefkowitz, et al., 2018). Dependiendo del género de orquídea, el CymMV ocasiona síntomas sistémicos de mosaico suave, manchas y estrías en hojas y flores, amarillamiento y caída de hojas (Pearson y Cole, 1986; Pant, Das, Pun, Ramachandran y Medhi, 2010). El ORSV, pertenece al género Tobamovirus, de la familia Virgaviridae; los viriones son elongados rígidos, con forma de bastón de aproximadamente 300 nm de largo (Lefkowitz et al., 2018). Los síntomas característicos de este virus son puntos necróticos en las hojas y estrías coloreadas en las flores. Las plantas infectadas presentan disminución del número y tamaño de escapos florales y flores, las cuales a su vez pueden manifestar deformaciones morfológicas (Hu, Ferreira, Wang y Xu, 1993; Zheng, Shen, Chen y Jan, 2010). Las coinfecciones con ambos virus resultan frecuentes; en este caso los síntomas observados son amarronamiento, estrías de color marrón y necrosis en flores, acompañados de pérdida de vigor en las plantas (Tanaka, Nishii, Ito, Kameya-Iwaki y Sommartya, 1997). Existen ocasiones en que plantas aparentemente sanas están infectadas con estos virus, por lo que la simple evaluación visual de síntomas no es un método confiable para determinar la condición sanitaria de las orquídeas (Zettler et al., 1990).

En los sistemas de cultivos intensivos y/o semiintensivos la forma más práctica de reducir los daños ocasionados por este virus consiste en la detección temprana y eliminación de las plantas infectadas a fin de asegurar la producción de material vegetal sano. A nivel comercial existen varios métodos para diagnosticar estas virosis, pero no son económicos ni se encuentran fácilmente disponibles para la mayoría de los floricultores. Este hecho favorece la multiplicación y comercialización de material infectado que luego impacta de manera negativa en las economías e industrias floricultoras de nuestra región.

Con la finalidad de promover la producción, multiplicación y comercialización de orquídeas de sanidad controlada, el objetivo del presente trabajo fue producir un antisuero policlonal para ser utilizado en el desarrollo de técnicas serológicas que permitan la detección de CymMV y ORSV.

\section{MATERIALES Y MÉTODOS}

\section{Purificación viral}

Se maceraron $70 \mathrm{~g}$ de hojas de Nicotiana glutinosa L. coinfectadas con CymMV y ORSV en $350 \mathrm{ml}$ de tampón fosfato de sodio (Na3PO4 0,1

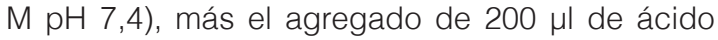
tioglicólico, 0,05 $\mathrm{g}$ de DIECA, 2,1 g de sulfito de sodio y $350 \mathrm{ml}$ de cloroformo. El homogenato se filtró y clarificó a $4355 \mathrm{~g}$ durante $20 \mathrm{~min}$. La fase acuosa se sembró en colchones de sacarosa al $20 \%$ en tampón fosfato de sodio y se centrifugaron a $113000 \mathrm{~g}$ por $1 \mathrm{~h} 30 \mathrm{~min}$. Los pellets se resuspendieron en $1 \mathrm{ml}$ del mismo tampón y se sembraron en un gradiente de cloruro de cesio fraccionado $10 \%$ - $40 \%$ en tampón fosfato 0,04 $\mathrm{M} \mathrm{pH}$ 7. El gradiente se centrifugó durante 3 h 30 min a $82700 \mathrm{~g}$. Se seleccionaron dos fracciones: la fracción A (FA) correspondiente a ORSV y la fracción B (FB) correspondiente a CymMV. Cada fracción se diluyó 1:10 en tampón fosfato y se centrifugó a $113000 \mathrm{~g}$ durante $1 \mathrm{~h}$ para eliminar el cloruro de cesio. Los pellets se resuspendieron en 200 l de tampón fosfato y se midió la concentración viral mediante espectrofotometría. El grado de pureza de los productos finales fue analizado al microscopio electrónico de transmisión (MET) JEOL 1200 (Jeol, Tokyo, Japan) mediante preparaciones rápidas según protocolo descripto por Kitajima y Nome, 1999.

\section{Inmunización y obtención de antisueros}

Las fracciones seleccionadas (FA y FB) se inyectaron de manera independiente a dos conejos machos californianos vía intramuscular. Inicialmente se inocularon $90 \mu \mathrm{g}$ de la FA y 125 $\mu \mathrm{g}$ de la FB, con el agregado de coadyuvante de Freud completo $(1: 1 \mathrm{v} / \mathrm{v})$ en un volumen final de 1 $\mathrm{ml}$. A los 24 días se aplicó un refuerzo del restante de la purificación, $30 \mu \mathrm{g}$ de la FA y $60 \mu \mathrm{g}$ de la FB en mezcla 1:1 v/v con coadyuvante de Freud incompleto. Se realizaron sangrías a los 14, 31 y 41 días después de la primera inoculación (dpi). Cada una de las sangrías fue inicialmente incubada a 37 ${ }^{\circ} \mathrm{C}$ durante $1 \mathrm{~h}$ y luego $1 \mathrm{~h}$ a $4{ }^{\circ} \mathrm{C}$. Posteriormente, se obtuvieron las fracciones séricas mediante centrifugación a $3024 \mathrm{~g}$ durante 5 min.

\section{Titulación de antisueros}

El título de cada antisuero (As) se evaluó mediante diluciones seriadas de las diferentes fracciones séricas en pruebas de NC-ELISA (Parent, 
Berlanger, Desjardins y Brisson, 1985) 1:100, 1:1000, 1:10000, 1:100000 en tampón antisuero [TBS (0,02 M Tris-HCl; 0,15 M NaCl; pH 7,4) + $2 \%$ de leche descremada en polvo]. Sobre una membrana de nitrocelulosa (BIO-RAD, California, USA) se adsorbieron $5 \mu$ de cada purificación viral de manera independiente y combinada (FA, $\mathrm{FB}$ y $F A+F B)$ y $5 \mu \mathrm{l}$ de orquídeas y nicotianas asintomáticas maceradas $1: 10 \mathrm{p} / \mathrm{v}$ en TBS $+0.05 \%$ Tween $20+0,01 \mathrm{M}$ DIECA + 0,02 \% NaN3. Las membranas fueron incubadas con los As primarios (diluciones seriadas) y un As secundario de IgG de cabra anti-conejo conjugado con fosfatasa alcalina (BIO-RAD, California, USA) diluido 1:3000 en tampón antisuero. Las membranas se revelaron en una solución de sustrato (tetrazolium nitroazul y fosfato bromocloroindolil, SIGMA) y agua destilada. La aparición de color púrpura fue considerada como muestra positiva.

\section{Purificación de gammaglobulinas y calibración de la técnica de Double antibody sandwich- enzyme-linked immunosorbent assay (DAS- ELISA)}

El As seleccionado se mezcló con igual volumen de sulfato de amonio saturado. La mezcla se dejó en agitación $1 \mathrm{~h}$ a temperatura ambiente y se centrifugó a $15300 \mathrm{~g}$ por 15 min. Luego, se colocó en una columna DEAE Sephacel y se dializó con tampón fosfato salino 0,5X [PBS (1 mM KH2PO4; $8 \mathrm{mM} \mathrm{Na} 2 \mathrm{HPO} 4 ; 0,13 \mathrm{M} \mathrm{NaCl} ; 3 \mathrm{mM} \mathrm{KCl})+0,02$ $\% \mathrm{NaN} 3, \mathrm{pH} 6,8]$. Se recogieron 10 fracciones de $1 \mathrm{ml}$ cada una y se determinó la concentración de inmunoglobulinas (Igs) mediante lectura en espectrofotómetro a $280 \mathrm{~nm}$. Se seleccionaron las fracciones que presentaron los dos valores de absorbancia más altos. La fracción de mayor absorbancia se conjugó con la enzima fosfatasa alcalina, y la segunda se utilizó como lg. Los anticuerpos anti CymMV+ORSV purificados se conjugaron con fosfatasa alcalina utilizando una solución de glutaraldehido al 1 \% (Sigma-Aldrich, EE. UU.). La preparación se mantuvo durante $4 \mathrm{~h}$ a temperatura ambiente y se dializó tres veces con PBS 1X para eliminar residuos de glutaraldehido. La reacción se bloqueó con el agregado de 0,05 \% de albúmina de suero bovino y se adicionó 0,01\% de NaN3 para su conservación.

Con el fin de calibrar la técnica de DAS-ELISA, las Igs e Igs conjugadas con fosfatasa alcalina se diluyeron 1:500, 1:1000, 1:1500 y 1:2000 en PBS, siguiendo el protocolo descripto por Clark y Adams, 1977. En cada placa de ELISA se colocaron purificaciones virales de plantas de orquídeas como controles positivos y nicotianas asintomáticas como controles negativos. Aproximadamente $0,1 \mathrm{~g}$ de tejido vegetal se trituró en tampón de extracción (PBS + $0.05 \%$ Tween $20+2 \%$ PVP-40.000, pH 6.8) en una dilución $1: 5 \mathrm{p} / \mathrm{v}$, y se sembraron $100 \mu \mathrm{l}$ de cada macerado por celda. Las placas se incubaron toda la noche a $4{ }^{\circ} \mathrm{C}$ antes de agregar la IgG-anti ORSV+CyMV conjugada. Los valores de absorbancia a $405 \mathrm{~nm}$ fueron determinados en un lector de ELISA (Dynex MRX II) a intervalos de 20 min después de la adición de p-nitrofenilfosfato como sustrato.

Una vez determinada la dilución de empleo de la Ig e Ig-fosfatasa alcalina para la técnica de DASELISA, se evaluaron 45 ejemplares tomados en diferentes invernaderos de Córdoba Capital. Las muestras consistieron de material vegetal (hojas y flores) provenientes de orquídeas que manifestaban síntomas característicos de infección viral (Figura 1), cada especímen se evaluó por duplicado. Los estudios incluyeron especies pertenecientes a los géneros Cattleya, Cymbiduim, Dendrobium, Oncidium y Phaleanopsis. Las lecturas con valores de absorbancia mayores a dos veces la media de los controles sanos fueron consideradas positivas.

\section{RESULTADOSY DISCUSIÓN}

El protocolo utilizado para purificar partículas virales mediante ultracentrifugación en gradiente de cesio permitió concentrar los viriones en dos bandas o fracciones bien definidas, denominadas FA y FB. Los valores de absorbancia obtenidos por espectrofotometría fueron de 0,18 $\mu \mathrm{g} \mathrm{ml}-1$ y 0,25 $\mu \mathrm{g} \mathrm{ml}-1$ para FA y FB, respectivamente, indicando la presencia de partículas virales en cada una de ellas. El análisis al MET (Figura 2) mostró que la FA presentó mayor cantidad de partículas rígidas de unos $300 \mathrm{~nm}$ de longitud correspondientes al ORSV, y escasas partículas virales flexuosas correspondientes a CymMV. La FB presentó mayor concentración de partículas flexuosas de unos $480 \mathrm{~nm}$ de longitud características del CymMV, y partículas aisladas rígidas de unos $300 \mathrm{~nm}$ de longitud correspondientes al ORSV.

Ambas fracciones fueron inoculadas de manera independiente a dos conejos y a partir de la titulación de las diferentes fracciones séricas obtenidas se seleccionó como As la sangría correspondiente a los $41 \mathrm{dpi}$ del conejo inyectado con la FA. Dicho As presentó alto título (dilución 1:10000) para la detección de ambos patógenos simultáneamente sin mostrar reacción con los testigos asintomáticos (Figura 3). El As presentó reacción positiva con ambas purificaciones virales 

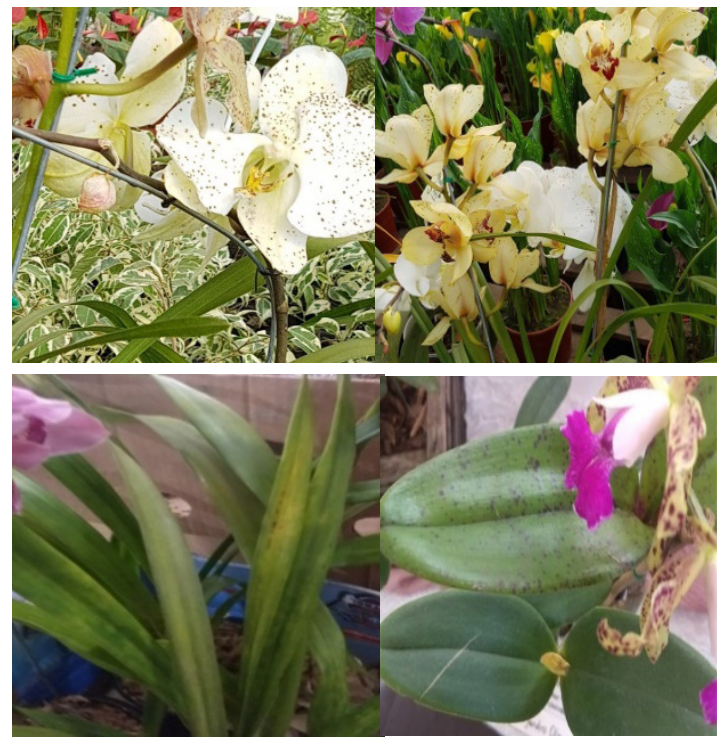

Figura 1. Orquídeas positivas por DAS-ELISA para CymMV y/o ORSV, manifestando (A) amarronamiento de las flores, (B) manchas puntiformes de color negro en flores, (C) manchas cloróticas y estrías necróticas en hojas y (D) puntos necróticos en las hojas.

(CymMV y ORSV) y con plantas de orquídeas que presentaban infección mixta. Esto se debió a que la FA inyectada al conejo contenía partículas pertenecientes a ambas especies virales. En contraste, aquellas orquídeas que se utilizaron como testigos enfermos para ORSV no reaccionaron con el As debido posiblemente a una baja concentración del virus ya que las plantas no manifestaban síntomas al momento de realizar las pruebas.

El As se utilizó para la detección de los patógenos mediante la técnica de DAS-ELISA. Las diluciones de uso seleccionadas fueron 1:500 tanto para la IgG-anti ORSV+CyMV como para la IgG-anti ORSV+CyMV conjugada con fosfatasa alcalina, ya que esta combinación presentó la mayor diferencia entre los valores de absorbancia de los testigos asintomáticos y los testigos enfermos. La técnica se puso a prueba a través de un estudio prospectivo llevado a cabo en agosto de 2018 en cuatro establecimientos comerciales de Córdoba Capital, Argentina. Aproximadamente el $22 \%$ de las muestras reaccionaron contra los anticuerpos policlonales para CymMV+ORSV, mientras que un total de 35 muestras resultaron negativas en las pruebas de DAS-ELISA (Tabla 1). Los análisis serológicos negativos podrían deberse a la época escogida para el muestreo puesto que las bajas

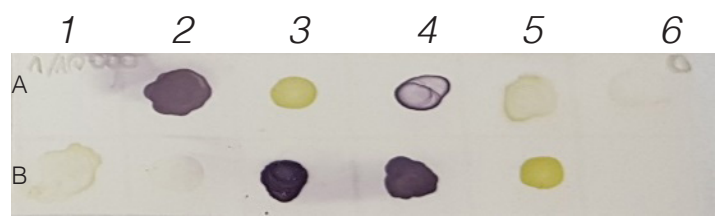

Figura 3. Detección de CymMV y ORSV por NC-ELISA utilizando la fracción sérica correspondiente a los 41 dpi con la FA.

A1 y B6, tampón; A2 y B4, nicotianas infectadas con CymMV+ORSV; $A 3$ y B5, orquídeas infectadas con ORSV; A4, FB (purificación de CymMV); A5 y B1, nicotianas sanas; A6 y B2, orquídeas sanas; B3, FA (purificación de ORSV).

A B

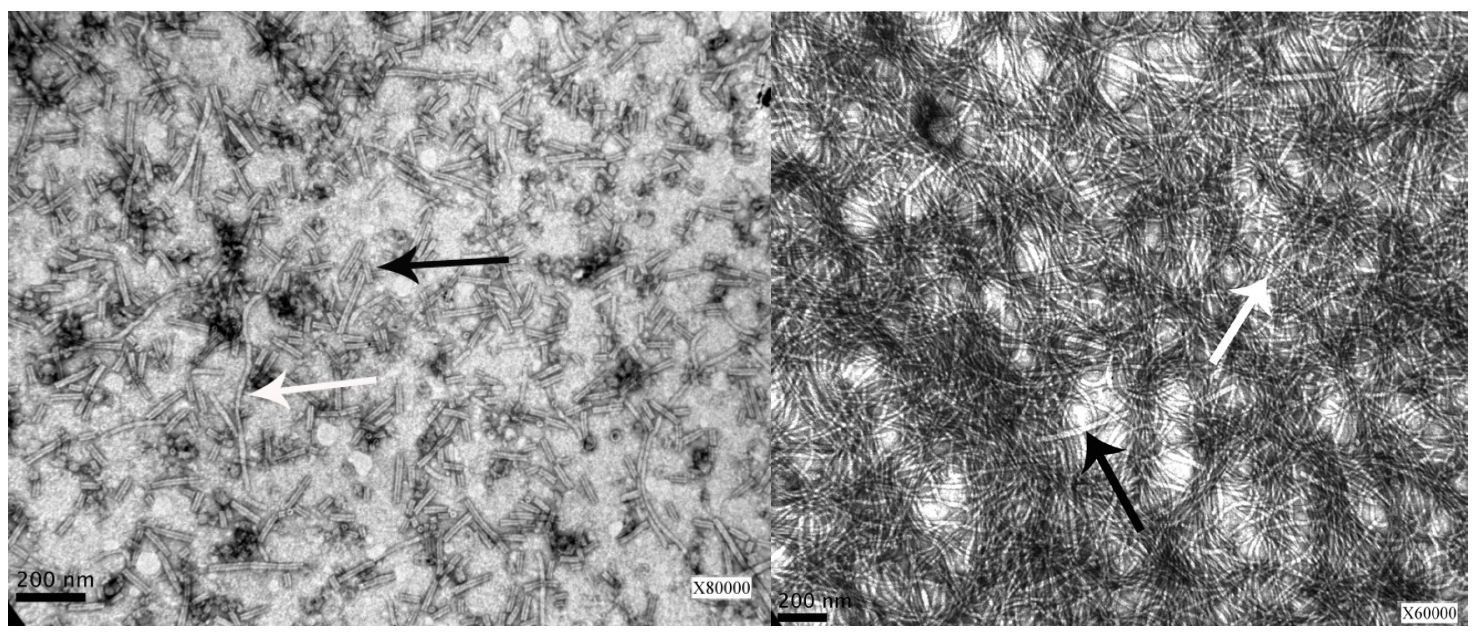

Figura 2. Preparados de fracciones recuperadas de purificación viral. (A) FA: las flechas negras indican partículas virales rígidas correspondientes a ORSV y las flechas blancas señalan partículas virales flexuosas de CymMV. (B) FB: las flechas blancas muestran partículas virales características de CymMV y las flechas negras señalan partículas virales pertenecientes a ORSV. 
Tabla 1. Cantidad de muestras de diferentes géneros de orquídeas recolectadas en viveros de la ciudad de Córdoba y analizadas por DAS-ELISA, utilizando anticuerpos policlonales para CymMV+ORSV

\begin{tabular}{lcccc}
\hline Vivero & Género & $N^{\circ}$ de muestras evaluadas & $\begin{array}{c}N^{\circ} \text { de muestras positivas } \\
\text { por DAS-ELISA }\end{array}$ & Procedencia \\
\hline \multirow{2}{*}{1} & Cattleya & 1 & 0 & desconocida \\
& Dendrobium & 2 & 0 & \\
2 & Oncidium & 1 & 0 & Buenos Aires \\
3 & Cymbidium & 8 & 2 & desconocida \\
& Phaleonopsis & 6 & 2 & \\
4 & Dendrobium & 11 & 1 & desconocida \\
\hline
\end{tabular}

temperaturas no favorecen la multiplicación de los virus en las plantas (Kassanis, 1957; ObrepalskaSteplowska et al, 2016). Otro motivo podría atribuirse a que los síntomas estuviesen asociados a otros factores como deficiencias nutricionales, fitotoxicidad, nemátodos u otras enfermedades causadas por hongos o bacterias (Simone y Burnett, 2002). Freitas-Astua, Rezende y Kitajima (1999), señalaron la dificultad de identificar infecciones virales en orquídeas basados solo en la observación de síntomas.

La ocurrencia de las virosis fue determinada en tres de los establecimientos relevados lo que indica una alta prevalencia de estos patógenos en los centros comerciales de la ciudad (Tabla 1). Este constituye el primer reporte de estas virosis en plantas de orquídea en la provincia de Córdoba, y es un indicador del tráfico de material infectado en nuestro país.

Los estudios realizados muestran que los reactivos serológicos desarrollados pueden emplearse en las pruebas de NC-ELISA y DASELISA, pudiendo explorarse su aplicación en otras variantes de ELISA, otras técnicas serológicas como Dot immuno binding assay (DIBA), Rapid immuno filter paper assay (RIPA) y Tissue blot immuno assay (TBIA), e incluso en técnicas de immuno electro microscopía (IEM) (Pant et al., 2013).

\section{CONCLUSIONES}

Se desarrollaron reactivos serológicos para el diagnóstico de CymMV y ORSV, los dos virus más importantes que infectan plantas de la familia Orchidaceae. La capacidad de estos reactivos para identificar CymMV, ORSV o infecciones mixtas en las plantas, permite realizar los análisis de manera más rápida y económica lo que representa una ventaja para detecciones a gran escala. Además, las herramientas de diagnóstico desarrolladas en este trabajo podrán ser utilizadas en futuras investigaciones, tendientes a promover la producción, multiplicación y/o comercialización de orquídeas libres de CymMV y ORSV, tanto en la provincia de Córdoba como en el resto del territorio nacional.

\section{BIBLIOGRAFÍA}

Arditti, J. y Ernst, R. (1993). Micropropagation of Orchids. New York, EE.UU.: John Wiley \& Sons.

Cánovas, S. E, Ballari, M. C. y Nome, C. F. (2016). First report of Cymbidium mosaic virus and Odontoglossum ring spot virus in Argentina. Australasian Plant Disease Notes, 11, 2. DOI: https:// doi.org/10.1007/s13314-015-0189-7

Clark, M. F. y Adams, A. N. (1977). Characteristics of the microplate method of enzyme linked immunosorbent assay for the detection of plant viruses. Journal of General Virology, 34 (3), 475-483.

Freitas-Astua, J., Rezende, J. A. M. y Kitajima, E. W. (1999). Incidence of orchid viruses in the state of Sao Paulo, Brazil. Fitopatologia Brasileira, 24,125-130.

Freuler, M. J. (2007). Orquídeas. Buenos Aires, Argentina: Editorial Albatros.

Hartmann, H. T. y Kester, D. E. (1991). Propagación de plantas: principios y prácticas. Distrito Federal, México: Editorial Continental.

Hu, J. S., Ferreira, S., Wang, M. y Xu, M. Q. (1993). Detection of Cymbidium mosaic virus, Odontoglossum ringspot virus, Tomato spotted wilt virus, and potyviruses infecting orchids in Hawaii. Plant Disease, 77, 464-468. DOI: https://doi.org/10.1094/PD-77-0464

Kassanis, B. (1957). Effects of changing temperature on plant virus diseases. Advance in Virus Research, 4, 221-241. DOI: https://doi.org/10.1016/S0065-3527 (08)60600-4 
Kitajima, E. W. y Nome, C. F. (1999). Microscopía electrónica en virología vegetal. En: Docampo, D. M. y Lenardon, S. L. (Eds.), Métodos para detectar patógenos sistémicos (59-87). Córdoba, Argentina: INTA-JICA.

Lefkowitz, E. J, Dempsey, D. M., Hendrickson, R. C., Orton, R. J, Siddell, S. G. y Smith, D. B. (2018). Virus taxonomy: the database of the International Committee on Taxonomy of Viruses (ICTV). Nucleic Acids Research, 46 (D1), D708-D717. DOI: https://doi. org/10.1093/nar/gkx932

Obrepalska-Steplowska, A., Renaut, J., Planchon, S., Przybylska, A., Wieczorek, P., Barylski, J. y Palukaitis, P. (2016). Effect of temperature on the pathogenesis, accumulation of viral and satellite RNAs and on plant proteome in peanut stunt virus and satellite RNA-infected plants: Corrected version. Frontiers in Plant Science7, 839. DOl: https://doi.org/10.3389/ fpls.2016.00839

Pant, R., Das, M., Pun, K., Ramachandran, P. y Medhi, R. (2010). Occurrence of Cymbidium mosaic and Odontoglossum ringspot viruses in orchid germplasm of Sikkim and Darjeeling hills, their identification and diagnosis. Indian Phytopathology, 63, 326-332.

Pant, R. P., Gupta, S., Hakmoasa, B., Meena, N. K., Vij, S. P. y Medhi, R. P. (Marzo 2013). Status of orchid virus diagnostics and their application in production of virus free planting material. En: R. P. Medhi, R. Devadas, N. Sailo, N. G. Debnath, Jaya Gogoi, S. L. Pattanayak (Eds.), National Dialogue on Orchid Conservation \& Sustainable Development for Community Livelihood (61-71). Gangtok, Sikkim, India: National Research Centre for Orchids, Indian Council of Agricultural Research.http://164.100.238.77/National\%20 Conference/Downloads/Abstracts $\% 20$ Cum $\% 20$ Sovenior\%20-\%20NC\%202013.pdf

Parent, J. G., Berlanger, F., Desjardins, S. y Brisson, J. D. (1985).. Dot-immunobinding for detection of tomato mosaic virus and potato virus $X$, infecting greenhouse tomatoes. Phytoprotection, 66, 53-57.

Pearson, M. N. y Cole, J. S. (1986). The effects of
Cymbidium mosaic virus and Odontoglossum ringspot virus on the growth of Cymbidium orchids. Journal of Phytopathology, 117 (3), 193-197. DOI: https://doi. org/10.1111/j.1439-0434.1986.tb00934.x

Pradhan, S., Regmi, T., Ranjit, M. y Pant, B. (2016). Production of virus-free orchid Cymbidium aloifolium (L.) Sw. by various tissue culture techniques. Heliyon, 2 (10), e00176. DOl: https://doi.org/10.1016/j. heliyon.2016.e00176

Rani, P., Pant, R. P. y Jain, R. K. (2010). Serological detection of Cymbidium mosaic and Odontoglossum ringspot viruses in orchids with polyclonal antibodies produced against their recombinant coat proteins. Journal of Phytopathology, 158 (7-8), 542-545. DOI: https://doi.org/10.1111/j.1439-0434.2009.01668.x

Simone, G. W. y Burnett, H. C. (2002). Diseases caused by bacteria and fungi. En: J. Watson (Ed.), Orchid Pests and Diseases (50-73). Delray Beach, Florida, Estados Unidos: American Orchid Society.

Tanaka, S., Nishii, H., Ito, S., Kameya-Iwaki, M. y Sommartya, P. (1997). Detection of Cymbidium mosaic potexvirus and Odontoglossum ringspot tobamovirus from Thai orchids by rapid immunofilter paper assay. Plant Disease, 81 (2), 167-170. DOI: https://doi. org/10.1094/PDIS.1997.81.2.167

Wong, S. M., Chng, C. G., Lee, Y. H., Tan, K. y Zettler, F. W. (1994). Incidence of Cymbidium mosaic and Odontoglossum ringspot viruses and their significance in orchid cultivation in Singapore. Crop Protection, 13 (3), 235-239. DOI: https://doi.org/10.1016/02612194(94)90084-1

Zheng, Y.-X., Shen, B.-N., Chen, C.-C. y Jan, F.-J. (2010). Odontoglossum ringspot virus causing flower crinkle in Phalaenopsis hybrids. European Journal of Plant Pathology, 128, 1-5. DOI: https://doi.org/10.1007/ s10658-010-9630-0

Zettler, F. W., Ko, N. J., Wisler, G. C., Elliott, M. S., y Wong, S. M. (1990). Viruses of orchids and their control. Plant Disease, 74 (9), 621-626. DOI: https://doi.org/10.1094/ PD-74-0621 